BNL $50628 / 53$

h. 1156

\title{
TECHNOLOGY ASSESSMENT AND IMPACT ANALYSIS OF SEPARATION METHODS APPLIED TO RADIOACTIVE WASTE MANAGEMENT
}

\author{
M. Goldstein, T. Gangwer, C. Braun, and R. Lester
}

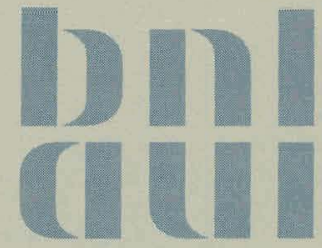

March 1977

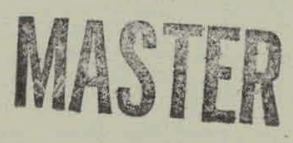

DEPARTMENT OF APPLIED SCIENCE

BROOKHAVEN NATIONAL LABORATORY ASSOCIATED UNIVERSITIES, INC. UNDER CONTRACT NO. EY-76-C-02-0016 WITH THE UNITED STATES ENERGY RESEARCH AND DEVELOPMENI ADMINISTRATION 


\section{DISCLAIMER}

This report was prepared as an account of work sponsored by an agency of the United States Government. Neither the United States Government nor any agency Thereof, nor any of their employees, makes any warranty, express or implied, or assumes any legal liability or responsibility for the accuracy, completeness, or usefulness of any information, apparatus, product, or process disclosed, or represents that its use would not infringe privately owned rights. Reference herein to any specific commercial product, process, or service by trade name, trademark, manufacturer, or otherwise does not necessarily constitute or imply its endorsement, recommendation, or favoring by the United States Government or any agency thereof. The views and opinions of authors expressed herein do not necessarily state or reflect those of the United States Government or any agency thereof. 


\section{DISCLAIMER}

Portions of this document may be illegible in electronic image products. Images are produced from the best available original document. 


\title{
TECHNOLOGY ASSESSMENT AND IMPACT ANALYSIS OF SEPARATION METHODS APPLIED TO RADIOACTIVE WASTE MANAGEMENT
}

\author{
M. Goldstein, T. Gangwer, C. Braun, and R. Lester
}

March 1977

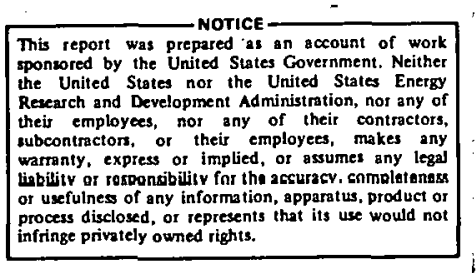




\section{NOT I C E}

This report was prepared as an account of work sponsored by the United States Govcrnment. Neither the United States nor the United States Energy Research and Development Administration, nor any of their employees, nor any of their contractors,

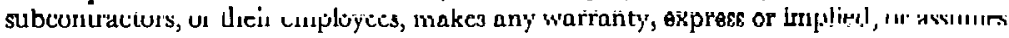
any legal liability or responsibility for the accuracy, completeness or usefulness of any information, apparatus, product or process discloscd, or represents that its use would not infringe privately owned rights.

Printed in the United States of America Available from

National Technical Information Service

U.S. Department of Commerce

5285 Port Royal Road

Springfield, VA 22161

Price: Printed Copy $\$ 4.00 ;$ Microfiche $\$ 3.00$

April 1977

300 copies 


\section{ABSTRACT}

A computer program has been written to estimate actinide production and accumulation in the high-level waste generated by an expanding nuclear economy over a 100-year period. The total weight of the actinides remaining in the biosphere was estimated for the recycle transmutation option and for two norecycle options.

A novel photochemical method for separating actinides from high-level waste or from each other is described based on selective ligand exchange reactions.

A preliminary cost comparison of plutonium separation using standard photoredox techniques has been accomplished and is reported. The energy requirements for photochemically separating all of the actinides are estimated to be only a fraction of the energy supplied by the fuel.

The potential advantages and disadvantages of actinide partitioning as a waste management option are discussed. Conclusions and recommendations are made regarding both the direction of technical development and policy analysis. 


\section{Introduction}

Recognizing the importance of waste separations, the U. S. Atomic Energy Commission initiated the Waste Partitioning Program in 1974. In1tial studies on the partitioning of high-level wastes showed that the program needed to be greatly expanded and that secondary processing of the wastes from conventional reprocessing streams was not a particularly desirable way to remove actinides from fission products.

The major controversies over nuclear power center around radioactive waste management and the safeguards issue. Both problems hinge on the fixing and controlling of the transuranic elements. One of the most critical facets of this process involves actinide partitioning. By removing $99.9 \%$ of the actinides, secure storage requirements of high-level waste are reduced from hundreds of thousands of years to less than one thousand years. Geological forecasting is considered reliable on this time scale. Several techniques have been suggested. The separated transuranics can be (1) transmuted to stable or shorter-lived fission products by recycling them in reactors, (2) placed in supersecure storage, or (3) rocketed off the earth.

Many of the problems associated with waste management could be simplified if good separation methods for various elements and isotopes were available. Recently the economic and technical feasibility of removing actinides and long-lived fission products from high-level waste by standard chemical processes has heen evaluated. 1,2

In the present study new photochemical processes involving the selective excitation of one or more actinides are being considered. These excited actinides exhibit enhanced vulnerability to ionization, dissociation, or chemical reactivity, which allows them to be separated from the feed material by physi- 
cal or chemical means. Selective photochemical processing is posstble because the frequencies of the lines in the spectrum are generally unique for most compounds, elements, and even isotopes. 


\section{Background}

Photochemical separation of nuclear waste and other advanced separation techniques offer some hope of reducing the cost of nuclear waste management. During the past decade public debate on the nuclear waste disposal issue has been extensive. This conflict arises both from technical limitations of waste handling and from certain institutional restrictions.

\section{A. The Waste Management Separation and Disposal Predicament}

Present-day management can be thought of in both humanistic and technological terms. The features of particular schemes can be related to present and future costs, percelved benefits, the time-scale of concern, and, in addition, the depth of responsibility felt for future generations. Most of the nuclear waste management schemes add an effective cost of only about $1 \%$ to the price of nuclear-powered electricity. Since the cost is so small in comparison to the time-scale of concern, perhaps dividing nuclear waste into distinct types might be worth the reduction in the cost of future risks if the risk of technical failure could be really lessened by such technology.

To illustrate this point let's consider dividing the wastes into longlived and short-lived species.

The first type contains the actinides, which have very long half-lives; that of plutonium-239, for example, is about 25,000 years. The radioactivity of type 1 materials (actinides and certain long-lived fission products) becomes dominant after about 500 years. The handling of the actinides can be thought of as a million-year problem. Thus, separation of this small volume of materials may offer many alternatives for disposal of the remaining larger volume of materials. 
In type 2 materials, long-lived fission products such as ${ }^{137} \mathrm{Cs},{ }^{85} \mathrm{Kr}$, and ${ }^{90} \mathrm{Sr}$ have half-lives approaching 30 years. After 700 years, only one tenmillionth of the radioactivity from these products would remain.

The taxonomy of options being considered has been recently discussed in some detail by Kubo and Rose. ${ }^{1}$ Whatever the final means of disposal, a separation technique that successfully alters the character of the waste has great value. Removing the actinides from the fission product waste stream reduces the 1-million-year problem to a 700-year problem, except for a very sma11. residue still in the million-year category. It may then be possible to treat the reduced million-year category by such techniques as neutron transmutation, e.g., recycling in fission reactors or possibly in fusion reactors.

Since reprocessing of spent reactor fuel is a commercial venture, uranium and plutonium are the only actinides extracted from the spent fuel elements. The degree of recovery for solvent extraction approaches $99.5 \%$ which is considered moderate at best. ${ }^{2}$ The use of laser photoexcitation and/or ion exchange resin ${ }^{2}$ techniques offers the potential of achieving separations of 99.9 to $99.99 \%$ of the actinides; leaving a residue considered ultrapure. Under these extreme extraction conditions, the residue would approach nontoxicity in less than a thousand years, with a concomitant decrease in the cost of handling this waste [i.e., if depth requirements are relaxed for the actinide free waste] and the danger of its release into the biosphere. Such reduction could amount to three orders of magnitude in the time scale required for secure storage (to keep material out of the biosphere).

Possible waste management schemes discussed in recent years are engineered above-ground or shallow burial storage, salt-mine disposal, granite-mine disposal, recycling of actinides, transmutation of fission products and/or acti- 
nides, glassification, melt in situ repositories, Antarctic rock, the continental ice sheet, the ocean bottom, and tectonic sinks. At present the lack of knowledge of the ocean bottom and tectonic sinks makes it unsafe to use them as repositories, given the long storage periods required for actinide materials. ${ }^{1}$

Three separate categories of waste management techniques are geological burial or long-term storage, removal from the biosphere by rocket, and transmutation of actinides into fission products for subsequent storage: The use of burial techniques has been questioned because geology over the long time-scales involved is not well understood. The cost of rockets and the potential danger of failure make transportation to the sun infeasible. One solution might be to transmute the long-lived isotopes to shorter-lived or stable isotopes and thus diminish the time-scale to one for which geological forecasting would be reliable. Transmutation will be feasible, however, only if adequate separation schemes are devised.

\section{B. Photochemical Separation Techniques}

Photochemical separation of nuclear waste is feasible because of the discrete ion absorption bands of these materials. Differences between the frequencies of lines in the spectra of the actinide ions are substantial. All photoseparation steps begin with the selective absorption of a photon, which enhances the vulnerability of the excited species to ionization, dissociation, or chemical reaction. Various modifications of this technique have been proposed.

One of the instruments most likely to produce the photons required for selective excitation is the laser. Most tunable lasers suitable for these tasks are about $1 \%$ efficient. ${ }^{3,4}$ Laser-excitation isotope separation has been shown to be feasible. ${ }^{3-11}$ Laser photochemical separation of actinides and fission products could well be even more feasible, since the specific absorption fea- 
tures of these materials are more easily matched from element to element than from isotope to isotope of a given element.

Most of the work on laser photoexcitation has been done in the gaseous or vapor phase. The amount of energy that photons can deposit per unit time in the vapor phase and the subsequent redistribution of the photon energy within the vapor phase is strongly dependent on the collision frequency between atoms or molecules. Energy redistribution takes place as a result of collision in the vapor phase. For processes such as partitioning of reactor waste involving electronic excitation but requiring nefther isotopic nor vibrational selectivity, the selectivity limitations are less confining. In this case 1aser photochemistry induced by electronic excitation could possibly be carried out without significant energy transfer effects. This technique is very promising to liquid phase separations.

Resonant excitation of one part of a molecule can be performed in liquid as well as other states. Its effectiveness in producing commercially useful reactions is currently being studied. ${ }^{3,4}$ Liquids seem to offer several advantages over gases in elemental or molecular separations using resonant electronic excitation, i.e., higher through put and higher absorbance in liquids should lower operating costs and capital costs should be lower in liquids as well because the technology for handling them on an industrial scale is simpler and further advanced than for gases.

Tunable visible and ultraviolet lasers could prove extremely useful. in the initiation of electronic excitation processes. One application would be the initiation of reactions among functional groups that are on a ligand complexed with the actinides. Individual actinides could be separated from each other or the actinides could be separated as a group from the fission products. High 
quantum yields might be obtained by using free-radical, self-propagating reactions. This scheme may also be applied to certain fission products, especially the rare earth elements. This technique is described in some detail in Section III.

One problem in the photochemical separation of nuclear waste is the effect of ionizing radiation. The concentration levels of actinides and fission products in nuclear waste treatment streams are such that essentially only solvents will be subject to direct damage by ionizing radiation. Therefore, decreased yields for photochemistry would result predominantly from free-radical or radiation-product thermochemistry. A system that did not react, e.g. (polymerize) when subjected to ionizing radiation but underwent a specific photochemical process would have great potential use in commercial-scale reprocessing and separation of wastes.

The development of tunable laser technology has enhanced the possibility of developing commercial-scale photochemical processes for the separation of nuclear waste at low cost and high separations. Limited work has been done on the photochemical reactions of nuclear waste and their application to separations. The main effort so far has been on the application of isotopic separation to uranium enrichment. The advantages of and rationale for using lasers as a means of applying photoexcitation to separations have been reviewed by K11pin. 12

The separation of photochemically induced reaction products may still involve the use of wet chemistry. A survey is being made of possible reaction and subsequent separation techniques for use in experiments on the economic feasibility of a commercially viable spent-fuel photochemical reprocessing scheme. 


\section{System Analysis}

Under this part of the program, estimates of actinide production in the future nuclear power industry have been made; and estimates of actinide partitioning costs for the Oak Ridge base case have been initiated.

A computer program has been written to estimate actinide production and accumulation in the high-level waste generated by an expanding nuclear economy over a period of up to a hundred years. Three options for treating the highlevel waste are considered: (1) no partitioning, i.e., a continuation of current practices; (2) partitioning of the high-level waste and separate storage of the actinides; and (3) partitioning of the high-level waste and recycling of the actinides in light-water reactors (LWR). Each option includes two suboptions: recycling of $\mathrm{Pu}$ in $\mathrm{LWR}^{\prime} \mathrm{s}$ or no recycling. It is assumed that actinide partitioning is performed in an add-on facility at the back of a reprocessing plant, as depicted in Figure 1 . Five actinide elements ( 17 isotopes) are considered: $\mathrm{U}^{234}$ to $\mathrm{U}^{238}, \mathrm{~Np}^{237}, \mathrm{Pu}^{239}$ to $\mathrm{Pu}{ }^{242}, \mathrm{Am}^{241}$ to $\mathrm{Am}^{243}$, and $\mathrm{Cm}^{242}$ to $\mathrm{Cm}^{245}$. :

The separation efficiencies for these isotopes in the reprocessing plant and in the actinide partitioning facility are treated as variable parameters. Data on actinide inventory in the spent fuel, assuming partitioning and recycling, were taken from ref. 13. Simplified semiempirical burnup curves predicting for each actinide isotope its production as a function of time and recycle rate were constructed: A more elaborate treatment of actinide production and burnup will be made when fuel burnup codes such as ORIGEN or ALTHEA become available. The evolution of the nuclear power industry and in particular that fraction represented by the $L W R^{\prime}$ 's is an input data set specified by the user. The program output includes the annual weight, or amount, of actinides handled 


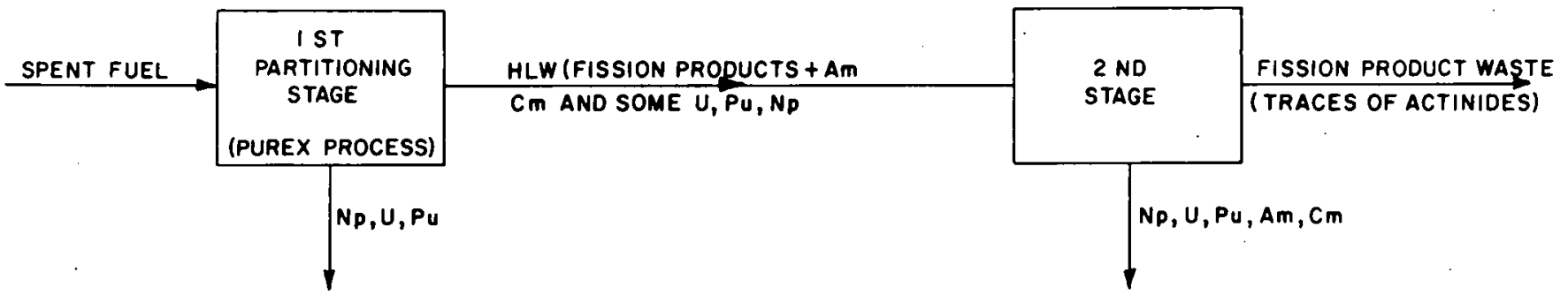

Figure 1. Reprocessing schematic. 
by the fuel cycle industry under each of the three waste management options shown in Table 1.

Initial results for option 1 (no plutonium or actinide recycling) were compared with similar results recently published by Ang and Pigford of UCLA. ${ }^{14}$ Good agreement between the two sets of results was obtained for all the actinide elements treated at BNL. The effects of increased actinide production in the recycling of plutonium in LWR's and of actinide "ratcheting" (increase in higher actinide production due to recycle) in the recycling and transmutation of actinides were considered. Ihis program is useful in that it delineates

Table 1

Total Weight of Actinides in the Blosphere by the Year 2075 .

\begin{tabular}{|c|c|c|c|}
\hline & $\begin{array}{l}\text { Option } \\
(100-y \times \text { LWR) } \\
\end{array}$ & $\begin{array}{l}\text { Actinides in } \\
\text { Storage (tons) } \\
\end{array}$ & $\begin{array}{l}\text { Actinides in } \\
\text { Fuel Cycle (tons) } \\
\end{array}$ \\
\hline 1. & $\begin{array}{l}\text { No partitioning, i.e., a continuation } \\
\text { of current practices }\end{array}$ & 1600 & $\sim 16$ \\
\hline 2. & $\begin{array}{l}\text { Partitioning of high-level waste } \\
\text { and eoparato storage }\end{array}$ & 1600 & .016 \\
\hline 3 . & Partitioning and recycling & 4 & $\sim 32$ \\
\hline
\end{tabular}

the magnitude of the actinide waste management problem for an evolving nuclear power economy. It is especlally useful in indicating the reduction in actinide management problems to be expected as partitioning and transmutation methods of various efficiencies are developed. It is planned to further develop and refine this program and to use it in conjunction with the detailed description of the nuclear fuel cycle that will shortly be made avallable as 
part of the ESNS/EMDB computer program being developed at Brookhaven National Laboratory.

\section{Photochemistry}

New processes involving the selective excitation of one or more species to a higher quantum state are being studied. These excited species exhibit enhanced vulnerability to ionization, dissociation, or chemical reactivity, which allows them to be separated from the feed material by physical or chemical means. Such excitation is possible because the frequencies of the absorption maxima in the optical spectrum are generally unique for most ions in solution.

Use of an ion's entire spectrum is not required to carry out a given photochemical reaction. For a given actinide ion, the wavelength and monochromaticity of the exciting laser or filtered lamp light required to produce the excited state which undergoes the desired photochemical reaction will be determined by the electronic absorption spectrum of the ground-to-excited state transition and the absorptions of any interfering solution components. One of the major advantages of a separation scheme based on photochemical reactions is that a component in a multicomponent mixture can be selectively excited and will react with a given component to the exclusion of all others. The only limitation on this photoselectivity is that any other component absorbing at the wavelength of interest should not undergo interfering photochemistry. Some of the advantages and limitations of photochemical processing are listed in Table 2. The important advantages may be the use of non-residual reagents which leave no contaminated solids upon solvent recycle. 
Table 2

Photochemical Processing

\section{Advantages}

1. Selective actinide ion excitation and photochemical reduction, oxidation, or ligand complexing

2.. Photochemistry readily varied by changing excitation wavelength

3. Reaction initiator (1ight) readily introduced into system

4. The use of non-residual reagents.

\section{Limitations}

1. Interfering absorptions by solvent or ions and quenching of excited state

2. Limited photochemical technology

3. Special window construction 
Two approaches to photochemical separation are being considered. The first, involving ligand photochemistry, is as yet unsubstantiated by experiment. The second is based on experimental results reported in the literature which are relevant to partitioning. ${ }^{15-17}$

\section{A. Ligand Photochemistry}

Some possible photochemical reaction systems for removing trace quantities of actinides have been formulated. In these new approaches, chelating agents are used and the ligands or chelating agents are made to react photochemically while bound to the actinides. The product can then be separated. Certain ligand compounds form complexes with $\mathrm{UO}_{2}^{2+}$ ions and other actinides. It is possible to envision a photochemical reaction such as ligand exchange:
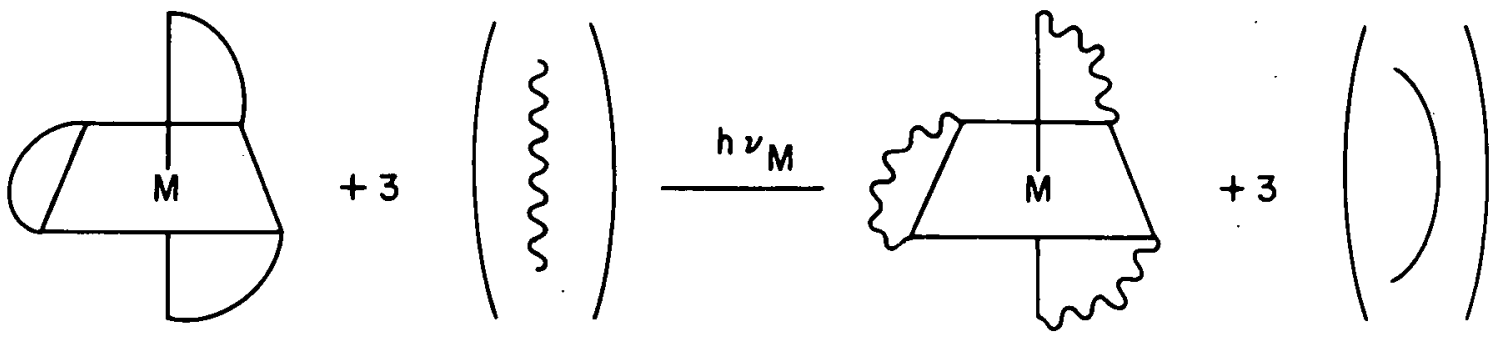

or

that is,

$$
\mathrm{MX}_{3}+3 \mathrm{Y} \stackrel{\mathrm{h} \nu_{\mathrm{M}}}{\mathrm{MY}} \mathrm{P}_{3}+3 \mathrm{X}
$$

where

(M) = M, actinide metal;

() $)=X$, a ligand that is complexed with actinides; and

$(\xi)=\mathrm{Y}$, a second ligand that is photochemically exchanged for ligand $\mathrm{X}$.

Such a selective ligand photoexchange could be utilized in a photochemical process to differentiate a given actinide (e.g., plutonium) from a mixture of actinides 


$$
\mathrm{UX}_{3}+\mathrm{NpX}_{3}+\mathrm{PuX}_{3}+3 \mathrm{Y} \stackrel{\mathrm{hv} \mathrm{Pu}}{\longrightarrow} \mathrm{PuY}_{3}+3 \mathrm{X}+\mathrm{NpX}_{3}+\mathrm{UX}_{3}
$$

with subsequent selective $\mathrm{PuY}_{3}$ partitioning by precipitation, solvent extraction, or further chemical reaction.

Another approach could be to form a differential reactive unit by substitution for the functional group $\mathrm{X}$ on the ligand $\mathrm{L}$. This process involves exciting the ligand L via absorption of light by the actinide and suhseguently transferring this absorbed energy to a specific functional group $\mathrm{X}$ on the ligand which is to be replaced by functional group Y (Intermolecular energy transfer reactions have been observed in analogous systems). For example,
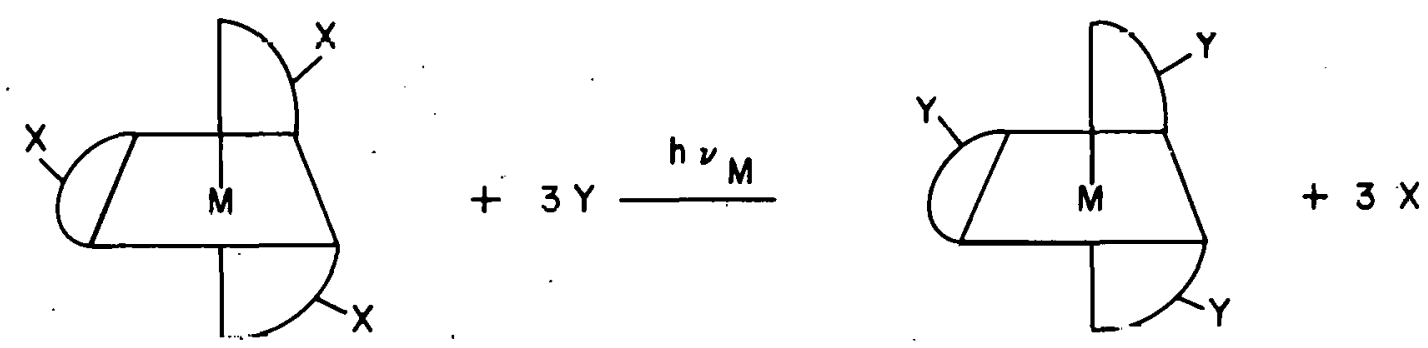

that is,

$$
M(L X)_{3}+\frac{h \nu_{M}}{M(L Y)_{3}}+3 X
$$

where

$$
\begin{aligned}
& X=L X, \text { ligand with functional group } X, \\
& Y=L Y, \text { ligand with functional group } Y,
\end{aligned}
$$

Here the selective 11gand function group photoexchange would differentiate, for example neptunium, from a mixture of actinides:

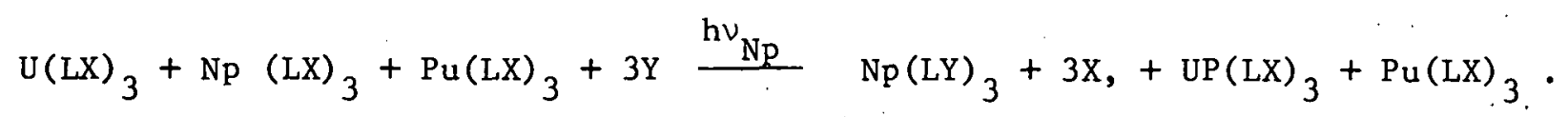


This would allow selective separation of $\mathrm{Np}(\mathrm{LX})_{3}$ by precipitation; solvent extraction, or further chemical reaction. Many variations of these two examples could be employed and should be investigated; e.g., a ligand that coordinates specifically with the actinide could be photochemically polymerized thus removing the entire group in one fell swoop.

The possibility exists that this technique can be extended to remove other hazardous elements of nonnuclear interest, such as $\mathrm{Cu}, \mathrm{Hg}$, and $\mathrm{Cd}$, from waste streams. Also, similar photochemical reactions can be used for removal of pollutants in the waste streams of industrial plants. The removal of trace amounts of $\mathrm{Hf}$ from $\mathrm{Zr}$ (essential in reactor materials because of the large neutron cross section of $\mathrm{Hf}$ ) may be photochemically feasible. As the world's supply of precious and semi-precious metals diminishes, the need increases for new, low energy intensive, separation processes to facilitate recycling and recovery from low-grade ores. The use of selective photochemistry or solarinduced photochemistry might conserve vast amounts of energy and reduce material losses. Many of these photochemical reactions would be easier than removing actinides from high-level waste because of the absence of $\gamma, \alpha$, and $\beta$ and because nonnuclear streams usually contain fewer impurities.

\section{B. Actinide Redox Photochemistry}

Highly selective photochemical oxidation or reduction of one actinide in the presence of others in elemental or molecular form would make possible separation by physical methods and avoid many of the problems of wet chemistry. Wet chemical reduction is often difficult to achieve and control and is usually not highly selective.

Selective, quantitative photochemical reduction of $U(V I)$ (at concentrations as low as micromolar) to $U($ IV) has been reported for solutions containing 
large quantities of various inorganic ions. Photoreduction of uranium ions by a large: number of organic molecules (e.g., alcohols, acids) and a number of inorganic molecules (e.g., iodide, mercurous ion) has been studied. Several uranyl systems undergo a photoprecipitation reaction, which indicates that this approach to partitioning may be a reliable option and should be explored.

The literature on uranium photochemistry is quite extensive, but the bulk of the data is 15 to 20 years old. Difficulties and contradictions in the data suggest that new studies are required to clarify the photochemistry of uranium. One. source of difficulty was the failure to regulate the oxygen content of the solutions in the early studies. Despite these limitations, there is sufficient evidence in several photoredox reaction systems to show that photochemistry has good potential for use in separating actinides. The uranium reactions should initially be studied and used as model systems in photochemical studies since the photochemical data are much more extensive for uranium than for the other actinides and experimentally much easier to handle (no radiation hazard).

Although the literature on plutonium photochemistry is limited, sufficient data exist to support the assumption that the photochemistry of plutonium and that of uranium is similar. Plutonium photochemistry provides several potential reactions for fractionating.

Several detailed studies of neptunium photochemistry lead to the conclusion that neptunium, plutonium, and uranium display similar photochemistry. However, significant differences in photoredox reactions will permit separation of this actinide.

These systems display a large range of adjustable variables in the conditions for photoreduction. This flexibility is encouraging, considering the process restrictions that usually evolve in going from laboratory bench to 
industrial production. Detailed experiments are required to optimize rates and yields and to study the various physical separation techniques. The literature on the separation of actinides indicates that sufficient spectral and wet chemistry data exist to allow design of an experimental program on photochemical reactions that show potential photoseparation properties.

A detailed report is being prepared on actinide photochemistry in relation to fractionation of nuclear waste streams in general and its utilization in improving the purex process in particular.

The main conclusion of the actinide photochemical literature studies is that the existing data indicate that certain photochemical redox reactions are very promising candidates for purex-type separations, having the advantage of using non-residual reagents; however, their application to partitioning $\mathrm{Am}, \mathrm{Cm}$, and other transuranics still needs to be demonstrated.

\section{Preliminary Cost Assessment of Laser Partitioning}

In nuclear fuel reprocessing plants the materials exist as ions in aqueous or organic phases. The absorption bands of the actinide ions extend over the region from $1100 \mathrm{~nm}$ through the ultraviolet. Current dye laser technology provides good coverage of most of this region, and thus one can avoid the difficult problem of developing a laser system to match the chemical system, as is being done in urantum 1sotope enrichment.

A preliminary cost analysis of photochemical laser separation of the plutonium has been made. The energy needed to excite one gram of plutonium is

$$
E(e V / g)=\frac{N_{0} E_{e x}}{M}
$$


where $\mathrm{N}_{0}$ is Avogadro's number, $\mathrm{E}_{\mathrm{ex}}$ is the excitation energy in eV needed to induce the desired photochemical reaction, and $M$ is the molecular weight of the plutonium ion.

The product of the fraction of absorbed light used to excite a given actinide in the process stream. $n_{t}$, the fraction of excited actinide which undergoes the desired photochemical reaction (i.e. the quantum yield) $\phi$, and the fraction of input light absorbed $n_{a b}$ is .

$$
\eta_{\text {abs }}=\eta_{t} \phi \eta_{a b}
$$

Therefore the photon source energy output utilized in carrying out the actinide photochemistry EL out, is given by

$$
\begin{aligned}
\mathrm{EL}_{\text {out }}(\mathrm{ev} / \mathrm{g}) & =\frac{\mathrm{E}}{\eta_{\text {alss }}} \\
& =\mathrm{Mri}_{t}^{\mathrm{N}_{0}^{\mathrm{E}} \mathrm{Ex}} \mathrm{ab}
\end{aligned}
$$

Defining the light source generation efficiency as

$$
\frac{\text { energy out }}{\text { energy in }}=\eta_{L}
$$

the energy input into the light source. (e.g. lamps or laser), EL in, required to separate one gram of actinide.is 


$$
\begin{aligned}
E L_{\text {in }}(e V / g) & =\frac{E}{n_{a b s} n_{L}} \\
& =\frac{N_{0} E}{M n_{t} \phi n_{a b} n_{L}}
\end{aligned}
$$

To convert to the proper units

$$
\begin{aligned}
E L_{\text {in }}(\mathrm{kWh} / \mathrm{g})= & E L_{\text {in }}(\mathrm{eV} / \mathrm{g}) \times 1.6 \times 10^{-19}(\mathrm{j} / \mathrm{eV}) \times \\
& \frac{1}{3600}(\text { watt } \mathrm{hRs} / \mathrm{j}) \times 10^{-3}(\mathrm{kWh} / \text { watt h) } \\
= & E L_{\text {in }}(\mathrm{eV} / \mathrm{g}) \times 4.4 \times 10^{-26}(\mathrm{kWh} / \mathrm{eV})
\end{aligned}
$$

Defining the cost of electricity as $C_{e}$ (mills/kWh), the electricity cost for actinide separation is

$$
\begin{aligned}
& C_{s}(\$ / g)=4.4 \times 10^{-26}(\mathrm{kWh} / \mathrm{eV}) \times \mathrm{EL}_{\text {in }}(\mathrm{eV} / \mathrm{g}) \times \\
& C_{c}(\operatorname{mills} / \mathrm{kWh}) \times 10^{-3}(\$ / \mathrm{mi} 11) \\
& C_{s}(\$ / g)=4.4 \times 10^{-29}(\mathrm{kWh} \$ / \mathrm{eV} \operatorname{mill}) \times \frac{6.02 \times 10^{23} \mathrm{E} e x}{M n_{\mathrm{abs}{ }^{n} \mathrm{~L}}}(\mathrm{eV} / \mathrm{g}) \times \\
& \mathrm{C}_{\mathrm{e}}(\mathrm{mills} / \mathrm{kWh}) \\
& =2.67 \times 10^{-5} \frac{E_{e x} C_{e}}{M n_{t}{ }^{\phi n} a b^{n} L}
\end{aligned}
$$


In the purex process, following initial separation of actinides (uranium, neptunium, and plutonium) from the fission products, the plutonium and the neptunium are separated from the bulk process stream. For photochemical removal of uncomplex plutonium ions from the waste stream, M in Eq. (6) would be 239 g/mole. The plutonium (IV) ion has an absorption at $\sim 6500 \mathrm{~A}^{\circ}$ with an extinction coefficient of $31 \mathrm{M}^{-1} \mathrm{~cm}^{-1}$. In terms of electron volts,

$$
\mathrm{E}_{\mathrm{ex}}\left(\mathrm{Pu}^{4+}\right)=\frac{1.24 \times 10^{4} \mathrm{eV} \mathrm{\AA}}{6500 \AA}=1.91 \mathrm{eV}
$$

It has been experimentally estimated ${ }^{18}$ that at initial process conditions (i.e. reduce nitric acid solutions containing all of the actinides and fission products) the fraction of light absorbed by all the ions except $\mathrm{Pu}^{4+}$ is $\sim 17 \%$ per centimeter. The initial $\mathrm{Pu}^{4+}$ concentration is $\sim 10^{-2} \mathrm{M}$ which gives a val,ue of $\sim 53 \%$ per $\mathrm{cm}$ for the fraction of light absorbed by this ion and therefore $\eta_{t}$ $\sim 0.76$. Assume the $\phi$ is equal to 0.1 (a value typically found in plutonium photochemical reactions and $\eta_{a b}$ is approximately unity when the system is properly designed) then $n_{\text {abs }} \sim 0.076$ for the initial process solution conditions. Since the parameter $\eta_{a b s}$ is a function of the $\mathrm{Pu}^{4+}$ concentration, the light source electricity cost, $C_{e}$, is $30 \mathrm{mills} / \mathrm{kwh}$ with a light source efficiency of $1 \%$ (i.e. laser or filtered lamps). 'To estimate the overall light source electricity cost shown in Table 4 for LWR-U fuel, ${ }^{2}$ the average of $\mathrm{C}_{S}$ between decades $\overline{\mathrm{C}}_{\mathrm{S}}$ was used. Thus the electricity cost per gram of plutonium is estimated to be $\$ 0.035$ for $99.99 \%$ recovery.

The size of a commercial reprocessing plant such as AGNS is $1500 \mathrm{Mt} / \mathrm{yr}$. For each ton of spent fuel there will be approximately $9 \mathrm{Kg}$ or approximately $1 \%$ plutonium. Therefore $1.7 \mathrm{Kg}$ of $\mathrm{Pu}$ will be processed per hour in a commer- 
Table 3

Concentration Dependence of $n_{\text {abs }}$ and $c_{s}$.

\begin{tabular}{|c|c|c|c|c|}
\hline$\left[\mathrm{Pu}^{4+}\right](\mathrm{M})$ & $\%$ Removed & $n_{t}$ & $n_{\mathrm{abs}}$ & $C_{s}(\$ / g)$ \\
\hline $10^{-2}$ & 0 & .76 & .076 & .00832 \\
\hline $10^{-3}$ & 90 & .30 & .030 & .021 \\
\hline $10^{-4}$ & 99 & .046 & .0046 & .137 \\
\hline $10^{-5}$ & 99.9 & .0044 & .00044 & 1.44 \\
\hline $10^{-6}$ & 99.99 & .00044 & .000044 & 14.4 \\
\hline
\end{tabular}

Table 4

Estimated Light Source Electricity Costs

\begin{tabular}{|c|c|c|c|c|}
\hline & Removed & $\bar{c}_{s}(S / g)$ & $\begin{array}{c}\text { Grams of } \mathrm{Pu}^{4+} \\
\text { Removed/MT* } \\
\end{array}$ & Cost $(\$)$ \\
\hline 0 & -90 & .015 & 8100 & 122 \\
\hline 90 & -99 & .079 & 810 & 64 \\
\hline & -99.9 & .787 & 81 & 64 \\
\hline \multirow{2}{*}{\multicolumn{2}{|c|}{$99.9-99.99$}} & 7.920 & 8.1 & 64 \\
\hline & & & & $\$ 314 / 9 \mathrm{~kg}$ \\
\hline
\end{tabular}

*The total content of $\mathrm{Pu}^{4+}$ was taken as $9 \mathrm{~kg}$ per metric ton of spent LWR-U fuel based on the data in reference 2 . 
cial size facility to accomplish that task. Phototchemically 2 MW of electrical power would be required. This large quantity of photons absorbed in the solution would produce a large but not unreasonable heat load which would have to be removed.

It is of interest to compute the cost of plutonium separation in units of equivalent mills/kWh and compare it with the nuclear power production cost. The cost of plutonium separation has sin far been calculated as $C_{S}=\$ 0.035 / g$, and we will take this figure as indicative of any transuranium photochemical separation. Because of the limited data available, an expression for the unit cost of separation of $G$ grams of plutonium per year must be formulated. Denoting laser capital cost as $C_{\dot{L}}(\$)$, balance of system capital cost as $C_{B}(\$)$, and rate of return as $=0.15 / y r$, the cost of capital is $0.15\left(C_{L}+C_{B}\right)(\$ / y r)$; the annual operating and maintenance cost is $\mathrm{C}_{\mathrm{OM}}(\$ / y r)$; and the annual cost of electricity is $C_{S}(\$ / g) G(g / y r)$. By summing the individual costs, the total cost in dollars per year is

$$
\mathrm{TC}(\$ / \mathrm{yr})=0.15\left[\mathrm{C}_{\mathrm{L}}(\$)+\mathrm{C}_{\mathrm{B}}(\$)\right]+\mathrm{C}_{\mathrm{MM}}(\$ / \mathrm{y} r)+\mathrm{C}_{\mathrm{s}}(\$ / g) \mathrm{G}(\mathrm{g} / \mathrm{yr})
$$

Thus, the unit cost can be expressed as

$$
U_{C}(\$ / g)=\frac{\left.0.15\left(C_{L}+C_{B}\right)+C_{O M}\right]}{G}+C_{S} .
$$

Betore converting these terms to equivalent mills/kWh, it is convenient to define the following quantities:

Reactor burnup of the reprocessed fuel $=R\left(M_{t h}{ }^{D / M} T^{T}.\right)$

Thermal efficiency of the reactor $=n_{t h}\left(\mathrm{MWe}_{\mathrm{MW}} \mathrm{th}\right)$ 
Grams of $\mathrm{Pu}$ in the high-level waste stream from the reprocessing plant per metric ton of fuel reprocessed $=W(g$ Pu/M.T. $)$.

The equivalent separation cost, ESC in $\mathrm{mlll} / \mathrm{s} / \mathrm{kWh}$, is

$$
\mathrm{ESC}=\frac{\mathrm{U}_{c} \mathrm{~W}}{\mathrm{R} n_{\mathrm{th}}} \times \frac{1000(\mathrm{mills} / \mathrm{S})}{24(\mathrm{hr} / \mathrm{D}) \times 1000\left(\mathrm{~kW}_{\mathrm{e}} / \mathrm{MW}_{\mathrm{e}}\right)}
$$

or

$$
\mathrm{ESC}=\frac{0.042 \mathrm{U}_{\mathrm{c}} \mathrm{W}}{\mathrm{Rn_{ \textrm {th } }}}
$$

The following data were taken from Table No. 7 on p. 11 of reference 19:

$$
\begin{aligned}
\mathrm{R} & =33,000\left(\mathrm{MW}_{\mathrm{th}} \text { Day/M.T. }\right) \\
\mathrm{n}_{\mathrm{th}} & =0.33\left(\mathrm{MW}_{\mathrm{e}} / \mathrm{MW}_{\mathrm{th}}\right) \\
\mathrm{W} & =9000(\mathrm{~g} \text { actinides/M.T. })
\end{aligned}
$$

Substituting these values into Eq. (9),

$$
\mathrm{ESC}=\mathrm{U}_{\mathrm{C}} \times 0.035
$$

Since insufficient data are available on the capital, operating, and maintenance costs of photochemical separation equipment, the equivalent separation cost will be parametrically calculated on the basis of the following ratios between the cost of electricity and the total cost of actinide separation: 


$$
C_{s}: U_{C}=0.1
$$

or

$$
C_{s}: \dot{U}_{c}=0.01
$$

Thus, the cost of electricity required is taken as either $10 \%$ or $1 \%$ of the total cost of separation. It is assumed that the actual figure will be somewhere in between, depending on the type of light source used to perform the photochemistry, e.g. a conventional lamp source separation facility is expected to have a total cost 10 times the electricity cost while the use of lasers would involve capital cost considerably higher. Therefore, the cost of electricity is taken to be 1 percent of total cost of separation by lasers. A second advantage of lamps is that their overall efficiency in the spectral band of interest is 3 to 5 times that expected of lasers. Thus the energy cost can be reduced by a factor of 3 or 5, that calculated for lasers with an assumed efficiency of 1 percent. But the most significant advantage of the lamp is that by using various optical techniques one can split off the spertral bands for plutonium, neptunium and other actinides from this single snurce. Thus hy appropriate engineering design the energy and capital cost for removing plutonium to $99.9 \%$ would be about equivalent to the cost of removing all the actinides, i.e. if they show similar photochemical activity as expected. Other important advantages of lamps include high reliability and low cost as well as being an existing technology.

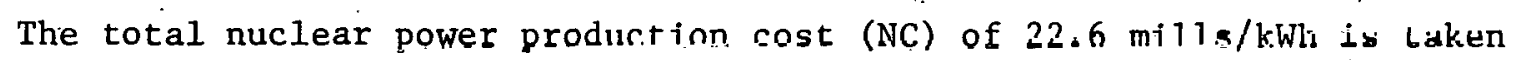
from p. 20 of ref. 28. The total cost of reprocessing and waste management 20 is $\mathrm{RC}=0.45 \mathrm{mills} / \mathrm{kWh}$. The results of the calculations are summarized in Table 5. The cost of transuranic separation is $0.12 \mathrm{mills}$ per $\mathrm{kWh}$, or five 
tenths of a percent of the nuclear power production cost. The cost of photochemical separation of the plutonium under our assumptions is between $27 \%$ and $2.7 \%$ of the reprocessing and waste management cost. Evidently photochemical separation of the plutonium would be a reasonable component of the nuclear power production cost.

Table 5

Equivalent Separation Cost Estimates

\begin{tabular}{|c|c|c|}
\hline & $\mathrm{C}_{\mathrm{S}} / \mathrm{U}_{\mathrm{c}}=0.01$ & $\mathrm{C}_{\mathrm{S}} / \mathrm{U}_{\mathrm{c}}=0.1$ \\
\hline$U_{c}(\$ / g)$ & 3.50 & 0.35 \\
\hline $\mathrm{ESC}(\mathrm{m} 11 \mathrm{ls} / \mathrm{kWh})$ & .12 & .012 \\
\hline $\mathrm{ESC} / \mathrm{NC}$ & $5.4 \times 10^{-3}$ & $5.4 \times 10^{-4}$ \\
\hline $\mathrm{ESC} / \mathrm{RC}$ & .27 & .027 \\
\hline
\end{tabular}

It is useful to calculate an energy input/output ratio for the plutonium separation process. The input energy (defined as the energy the photon source requires to separate the actinides) is given by Eq. (5). Substituting in the appropriate parameter values gives the $\mathrm{EL}_{\text {in }}$ value for plutonium of $1.17 \mathrm{kWh} / \mathrm{g}$. The energy output is defined as the energy generated by the fuel in a nuclear reactor before it is reprocessed. The energy input/output ratio, EIOR, can be formulated on the common basis of a metric ton of nuclear fuel reprocessed:

$$
\text { EIOR }=\frac{\mathrm{EL}_{\text {in }} \mathrm{W}}{\mathrm{Rn} \mathrm{th}_{\mathrm{h}}} \times \frac{1}{24(\mathrm{~h} / \mathrm{D}) \times 1000\left(\mathrm{~kW}_{\mathrm{e}} / \mathrm{MW}_{\mathrm{e}}\right)}
$$


Substituting numerical values in the energy ratio equation, we have

$$
\begin{aligned}
\text { EIOR } & =\frac{1.17 \times 9000}{33000 \times 0.33} \times 4.17 \times 10^{-5} \\
& =4.0 \times 10^{-5}
\end{aligned}
$$

for plutonium.

Thus the energy requirement for actinide separation is a fraction of the energy supplied by the fuel in the nuclear reactor. Note however, that the EIOR does not include the energy contribution for manufacture of photochemical devices and the process piping and shielding.

\section{A. Reactions}

In the second step of the purex process, plutonium is extracted from the tributylphosphate solution containing $\mathrm{U}, \mathrm{Np}$, and $\mathrm{Pu}$. This is accomplished by thermochemical reduction of $\mathrm{Pu}$ (IV) to $\mathrm{Pu}$ (III) by ferrous sulfamate, which results in byproducts that introduce solid waste and recycling problems. By carrying out this step with nonresidual photochemical reagents one can avoid many of these problems. For example consider the hydrngen peroxide reduction of $\mathrm{Pu}(\mathrm{IV})$

$$
2 \mathrm{Pu}^{4+}+\mathrm{H}_{2} \mathrm{O}_{2} \stackrel{\mathrm{hv}}{\longrightarrow} 2 \mathrm{Pu}^{3+}+2 \mathrm{H}^{+}+\mathrm{O}_{2}
$$

Figure 2 shows a typical concentration/time plot for thic reaction in the absence and presence of a photon source where the decrease of $\mathrm{Pu}^{4+}$ is due to formation of $\mathrm{Pu}^{3+}$. It should be noted that the faster one inputs the light the faster the reaction will proceed. By carrying out the hydrogen peroxide photoreduction of $\mathrm{Pu}(\mathrm{IV})$ to $\mathrm{Pu}(\mathrm{III})$ the purex byproducts and recycling problems are 


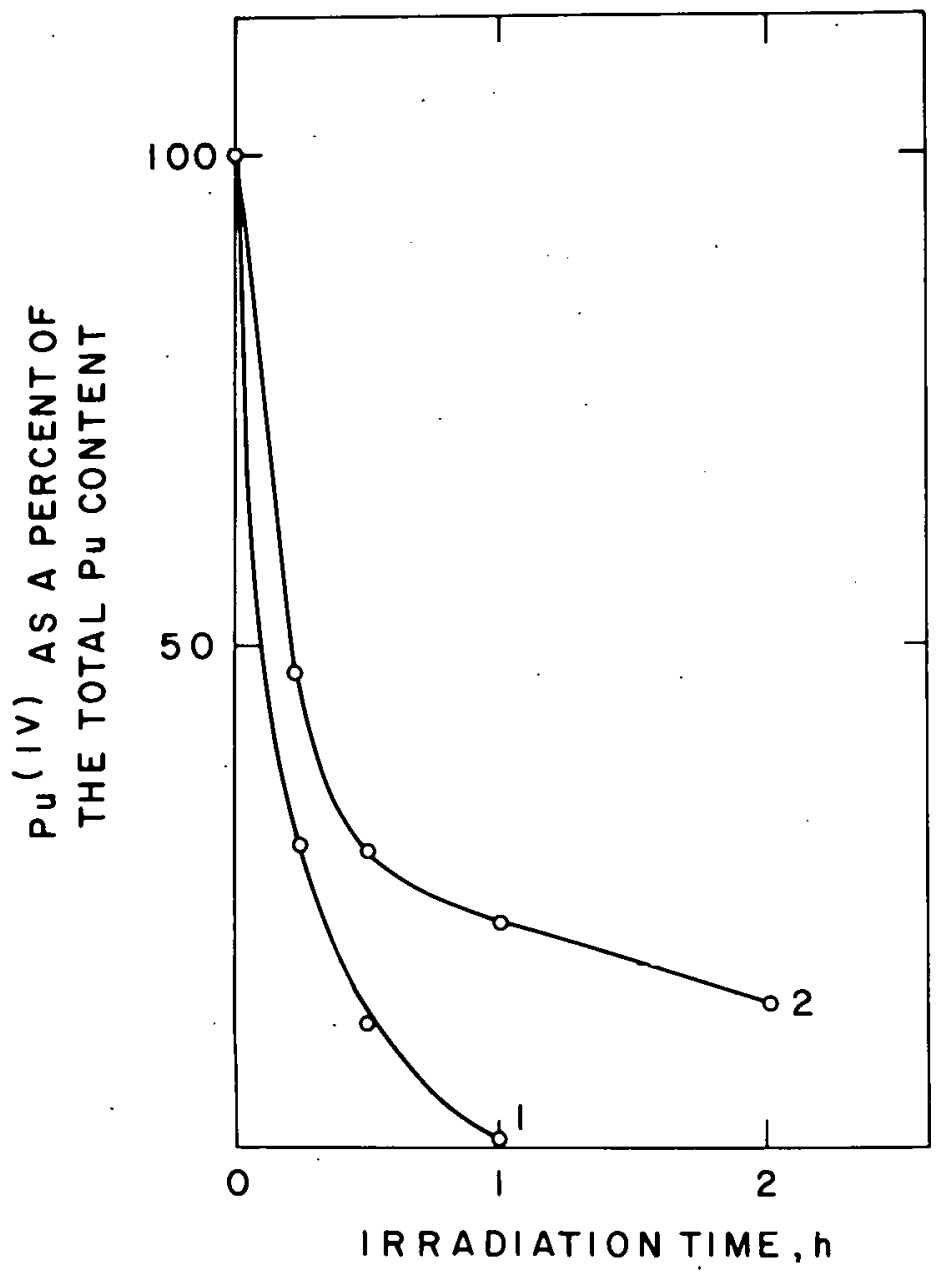

Figure 2. Reduction of $\mathrm{Pu}(\mathrm{IV})$ to $\mathrm{Pu}(\mathrm{III})$ in a solution containing $2 \% \mathrm{H}_{2} \mathrm{O}_{2}$ in relation to time. 1) With irradiation; 2) without irradiation. 
eliminated. The addition of hydrogen peroxide to $\mathrm{Pu}($ IV) solutions results in a bonus. (A parameter of importance for the actinide photochemistry is the extent to which added photochemical reagents alter the absorption spectra.) (Complexing by $\mathrm{H}_{2} \mathrm{O}_{2}$ leads to plutonium species which have increased absorption band intensities. Recent work at $\mathrm{ORNL}^{21}$ by Bell has shown that this reduction with formic acid or hydrazine instead of $\mathrm{H}_{2} \mathrm{O}_{2}$ may be more suitable for a commercial process where these reactions produce $\mathrm{CO}_{2}$ and $\mathrm{N}_{2}$ as byproducts respectively. 


\section{CONCLUSIONS AND RECOMMENDATIONS}

Preliminary assessment of the role of photochemistry in handling nuclear materials has been accomplished. Some preliminary estimates of energy costs due to photon requirements and spent fuel reprocessing indicate that this technique is promising. Even though these cost estimates appear very favorable, the suitability of photochemistry for commercial spent fuel reprocessing awaits verification by process testing. Possible problems could arise due to the fission products which can either absorb light intended for the actinide or can deactivate an excited actinide prior to successful completion of the photochemical reaction, i.e., a reduction or oxidation which allows it to be separated from the other species. These potential problems can be avoided in commercial spent fuel reprocessing by performing photoredox reactions on streams which contain a minimum of fission products.

If photochemistry is to be applied to the partitioning of actinides for high level waste, a large number of fission products such as ruthenium, rhodium, and palladium would have to be removed. Therefore, the actinide and lanthanides could be chemically partitioned from the other fission products as has been suggested by the investigators at Oak Ridge (ORNL 5012). Photochemistry may have cost and efficiency advantages in separating the actinide from the lanthanides and could serve as an option to the ion exchange or talespeak methods presently under consideration for that purpose.

The outlook for successful application of photochemical separations in nuclear processes other than spent fuel reprocessing is extremely favorable. Therefore, it is recommended that these processes be examined for possible photochemical modification. If substantial benefit from utilizing non-residual photochemical reagents would warrant the expense of process development, then work 
should proceed. It is suggested that weapons reprocessing at Rocky Flats is an ideal reprocessing system for photochemical process development. In such systems, large quantities of transuranic-contaminated solids could be eliminated, and secondary reprocessing and distillation of solvent streams may be greatly reduced. The impact of this volume reduction in nuclear waste from the Rocky Flats process and other similar waste streams might significantly reduce waste handling costs and environmental risks.

It should be pointed out that even though the scientific feasibility of photochemlcal separations has been established, engineering and practical limitations may prevent successful development. Therefore, it is recommended that these engineering parameters be investigated for photochemical processes using both commercial light sources (lamps) and lasers. Preliminary analysis of existing technology indicate lamps are far superior to lasers as a source of photons for actinide separation (both from a capital and operation cost viewpoint). It should also be pointed out that the development of photochemical reprocessing in Rocky Flats type nuclear processes would stand as a technological base for the development of a photochemically modified purex process to be applied to reactor spent fuels.

With regard to the question of the effect of partitioning and transmutation on nuclear fuel cycle economics, analysis has shown that implementation of nuclear power compared to the alternatives such as coal would not significantly be altered in future energy scenarios out to the year 2000, i.e., assuming increased fuel costs up to $100 \%$ due to separation and recycle. However, no conclusion can be made on the impacts of partitioning until the safety of the entire fuel cycle is established in the same way that the Rasmussen study did this for nuclear reactors. It is recommended that a similar independent analysis be 
conducted for the entire fuel cycle. Then a comparative risk benefit of partitioning will be feasible and in order.

Preliminary estimates of a reduced actinide inventory due to transmutation must be verified, but even if confirmed this reduction in itself is not reason enough to select the waste management option of partitioning and transmutation. It must be shown that the partitioning-recycle option reduces the overall risk from the actinides; i.e., we must know if the danger from actinides in the ground is greater or less than the risk from handling, reprocessing, and transporting these materials within the fuel cycle.

Another important point is that the actinide partitioning option only makes sense if one looks at the whole picture including low level and intermediate level (including military) transuranic wastes (the low level wastes constitutes about $1 / 2$ of the transuranic materials). This large portion of the transuranic waste is in the form of high volume material, and it is more difficult to partition than HLLW by conventional techniques.

There are several advantages to processing the large volumes of low level waste with high temperature separation techniques. Although it is much too early in the game to rule out aqueous processing, it may be that some of the high remperature methods would have several inherent advantages for handling the great variety of materials because of the greater range of solubility and because of the volume-reducing capability of these techniques. Therefore, it is recommended that before any policy decisions can be made on partitioning high level. commercial waste, a complete review of separation techniques be made for low level waste, and in fact all transuranic waste, in order to determine the feasibility and benefit of total partitioning. This may be more difficult to justify than HLW partitioning. 


\section{REFERENCES}

1. A. S. Kubo and D. J. Rose, Radioactive waste management, Science 182, 1205 (1973).

2. W. D. Bond and R. E. Leuze, Feasibility Studies of the Partitioning of Commercial High-Level Waste Generated in Spent Nuclear Fuel Reprocessing: Annual Progress Report for FY-1974, ORNL-5012, Jan. 1975.

3. R. Jensen, LASL, Private communication, March, 1975.

4. R. Robinson, LASL, Private communication, March, 1975.

5. D. N. Stacey, Isotope shifts and nuclear charge distributions, Rep. Prog. Phys. 29, 171-215. (1966).

6. A. F. Golovin and A. R. Striganov, The isotope effect in the spectra of the heavy elements, Usp. Fiz. Nauk 93, 111-50 (1967) [Sov. Phys. Usp. 10, 658-77 (1968) (Eng1. Trans1.)]; see also W. H. King, The Estimation of mass shifts in optical isotope shifts, J. Phys. $\underline{B} \underline{4}, 288-95$ (1971).

7. J. Artaud, J. Blaise, and S. Gerstenkorn, Isotopic analysis by emission spectroscopy, in Proc. 2nd UN Int. Conf. Peaceful Uses At. Energy, Geneva, 1958, Vol. 28, pp. 632-8, UN, New York, 1958 .

8. J. Artaud, J. Blaise, and S. Gerstenkorn, Isotopic analysis of lithium by optical spectroscopy: I. Utilization of the line $\lambda=4603 \mathrm{~A}$ (in French), Spectrochim. Acta 10, 110-18 (1958).

9. E. W. Burke, Jr., Isotope shift in the first three spectra of boron, Phys, Rev. 99, 1839-41 (1955).

10. G. Rossi, Z. Hainski, and N. Omenetto, Isotopic analysis of uranium by an optical spectral method: II. Determination of low $235 \mathrm{U}$ concentrations with a hollow cathode source and photographic recording, in Proc. 14th Collog. Spectrosc. Int., Debrecen, Hungary, Aug. 1967, Vol. II, pp. 67585, Adam Hilger Ltd., London, 1967.

11. H. Kirchkof, Determination of the isotopic composition of lead samples by the atomic absorption method, Spectrochim. Acta 24B, 235-41 (1969).

12. D. Kilpin, Isotope Separation Using Laser Excitation, WRE-TM-494 (WR and D), Oct. 1971.

13. High-Leve1 Radioactive Waste Management Alternatives; BNWL-1900, May, 1974.

14. Kiat Peon: Ang, "Quantities of Actinides in Nuclear Reactor Fuel Cycles", PhD Thesis - Lawrence Berkeley Lab, April, 1975. 
15. M: Goldstein and T. Gangwer, Applications of Actinide Photochemistry to Waste Partitioning, in Proceedings of the Conference on Actinide Removal from Acidic Wastes, Golden, Colorado, May, 1976.

16. T. Gangwer, Partitioning of actinide elements from high-level waste using laser photochemical methods, in Proc. U.S. Nuclear Regulatory Commission Workshop on Waste Partitioning as an Alternative in the Management of Radioactive Wastes, Seattle, June 1976, NR-CONF-001.

17. T. Gangwer, Photochemistry Relevant to Nuclear Waste Separations: $\underline{\text { A Feas- }}$ ibility study, BNL report, in preparation.

18. G. DePorter, LASL, Private communication, August 1976.

19. BNWL-1876, 1974 .

20. The Nuclear Industry, WAS-1147-74, 1974.

21. J. Bell, ORNL, private communications. 